\title{
Green Synthesis, Composition Analysis and Surface Active Properties of Sodium Cocoyl Glycinate
}

\author{
Guiju Zhang*, Baocai Xu, Fu Han, Yawen Zhou, Hongqin Liu, \\ Yunxia Li, Lu Cui, Tingting Tan, Nan Wang \\ School of Food and Chemical Engineering, Beijing Key Laboratory of Flavor Chemistry, Beijing Higher Institution Engineering \\ Research Center of Food Additives and Ingredients, Beijing Technology and Business University, Beijing, China \\ Email: "zhangguiju2013@yahoo.com
}

Received June 11, 2013; revised July 12, 2013; accepted August 13, 2013

Copyright (C) 2013 Guiju Zhang et al. This is an open access article distributed under the Creative Commons Attribution License, which permits unrestricted use, distribution, and reproduction in any medium, provided the original work is properly cited.

\begin{abstract}
Cocoyl glycine was synthesized directly from coconut oil and sodium glycinate in yield of $87 \%$. IR, ESI-MS and LC/MS analysis results showed that cocoyl glycine consists of a series of acyl glycines with different acyl chain lengths, and the proportion of each component was consistent with the composition of fatty acids derived from coconut oil. The surface tension and the Critical Micelle Concentration (CMC) of corresponding sodium salt were evaluated. The result showed that sodium cocoyl glycinate reduced the surface tension of water to a minimum value of approximately 33 $\mathrm{mN} \cdot \mathrm{m}^{-1}$ at $\mathrm{CMC}$ of $0.21 \mathrm{mmol} \cdot \mathrm{L}^{-1}$.
\end{abstract}

Keywords: Synthesis; Composition; Surface Properties; Cocoyl Glycine; Sodium Cocoyl Glycinate

\section{Introduction}

Acyl amino acid surfactants are considered modified fatty acids in which the hydrocarbon chains are interrupted by an amido linkage, which imparts greater solubility and enhances adsorption characteristics compared to the parent fatty acids [1]. These surfactants are widely used in consumer product formulations because they interact favorably with skin and hair, and are of low toxicity and hypoallergenic, also do not cause eye irritation, and are readily biodegradable [2,3]. Moreover, acyl amino acid surfactants have better stability towards hard water and high concentration electrolyte, and many of them possess excellent emulsifying and antimicrobial activities, which render them valuable as additives in the formulation of food, cosmetics, personal care and pharmaceutical products $[1,4-5]$.

Acyl amino acids are produced commercially by the Schotten-Baumann reaction in which condensation of a fatty acyl chloride with an amine is carried out under alkaline conditions [6-10], and the crude sodium salt is acidified to liberate the free fatty amino acid, which can be neutralized to form the corresponding salts, taking cocoyl glycine as an example shown in Figure 1, where $\mathrm{RCO}$ - represents the fatty acids derived from coconut

${ }^{*}$ Corresponding author. oil.

However, the aforementioned process for acyl amino acids production usually uses toxic and irritant fatty acyl chlorides, as well as $\mathrm{PCl}_{3}$ or $\mathrm{SOCl}_{2}$, giving rise to environmental pollution and also leading to undesirable odor and irritation of final products, which cannot be got rid of even by further purification steps. Some researchers have endeavoured to overcome such drawbacks by using biocatalysis instead of chemical process [11-14]. Indeed, enzymatic reactions are alternative owing to their mild reaction conditions and the limited use of chemicals. Nevertheless, bio-catalytic reactions usually require long reaction time and high-cost, and bring about relatively low yields in some cases.

In this work, the green synthesis of cocoyl glycine directly from coconut oil and sodium glycinate was introduced, shown in Figure 2, where RCO-represents the fatty acids derived from coconut oil.

This process is simplified compared to Schotten-Baumann condensation. Most important of all, it is environmental-friendly, because of employing no toxic and irritant reagents. This paper describes the green production, characterization and composition analysis of cocoyl glycine using IR, ESI-MS and LC/MS methods, as well as surface active properties of sodium cocoyl glycinate. 


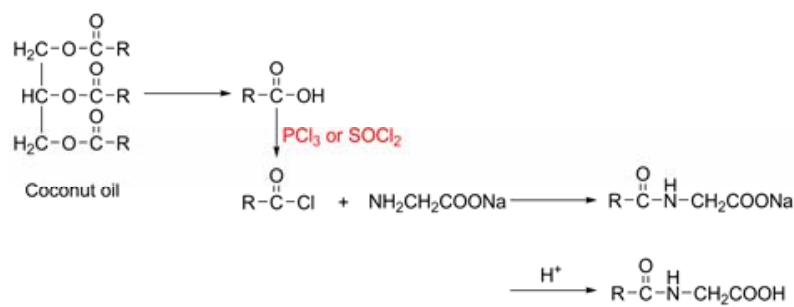

Figure 1. Schotten-Baumann reaction to produce cocoyl glycine.

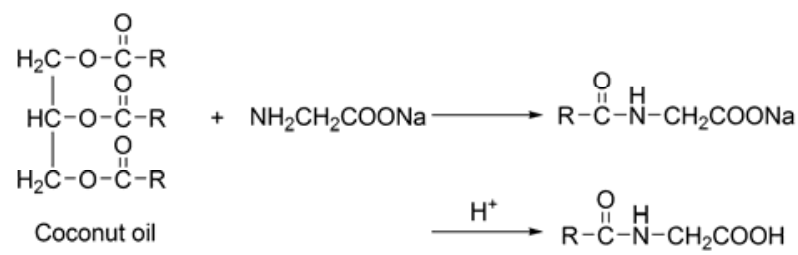

Figure 2. Green synthesis of cocoyl glycine from coconut oil and sodium glycinate.

\section{Experimental Section}

\subsection{Materials}

Coconut oil was obtained from Kerry Oleochemical Industrial Co. Ltd., Shanghai. Glycine was provided by Biodee Biotechnology Co., Ltd., Beijing. Methanol and Formic acid (HPLC grade) were purchased from Dikma Technologies Inc., Beijing. Other materials and reagents were used as received.

\subsection{Experimental Methods}

The infrared (IR) spectra were recorded on a Thermo Fisher Nicolet iS10 FT-IR Spectrometer at room temperature (KBr).

Composition analysis of cocoyl glycine was performed by high-performance liquid chromatography (HPLC) coupled on-line to an electrospray ionization mass spectrometer (ESI-MS). For HPLC/MS the following instrumentation was used: LC-20A HPLC system (Shimadzu, Japan) was coupled with an API3200 triple-quadrupole mass spectrometer (AB SCIEX, the United States). Column: XAqua C8, $4.6 \times 250 \mathrm{~mm}, 5 \mu \mathrm{m}$ (Huapu, China). The HPLC solvents were solvent A (deionized water $/ 0.1 \%$ formic acid) and solvent $\mathrm{B}$ (methanol $/ 0.1 \%$ formic acid), while $\mathrm{A} / \mathrm{B}$ was $24 / 76(\mathrm{v} / \mathrm{v})$ and flow rate was $0.3 \mathrm{~mL} / \mathrm{min}$.

Aqueous solution equilibrium surface tension values were obtained by the Wilhelmy plate method using a Dataphysics tensiometer, model DCAT11. The CMC value was taken at the intersection of the linear portions of the plots of the surface tension against the logarithm of the surfactant concentration. Surfactant solutions were prepared with distilled, deionized water. Sample temperatures were stable at $25^{\circ} \mathrm{C} \pm 0.2^{\circ} \mathrm{C}$.

\subsection{Synthesis of Cocoyl Glycine}

Sodium glycinate was obtained from glycine neutralized with $\mathrm{NaOH}$ aqoeous solution in a three-necked flask. After the water was evaporated, stoichiometric coconut oil and catalytic amount of $\mathrm{CH}_{3} \mathrm{ONa}$ were added with stirring, and the reaction solution was heated to about $160^{\circ} \mathrm{C}$ and stirred for $4-5 \mathrm{~h}$. The reaction mixture was cooled to $60^{\circ} \mathrm{C}$ and dissolved in water with acidification by $\mathrm{HCl}$ solution, leading to a white precipitate of cocoyl glycine in a yield of $87 \%$.

\section{Results and Discussion}

\subsection{Characterization of Cocoyl glycine}

IR spectra of coconut oil and cocoyl glycine are shown in Figure 3. In comparison to starting material coconut oil, the appearance of new peaks at about $3310 \mathrm{~cm}^{-1}$ and $1643 \mathrm{~cm}^{-1}$ indicates the formation of amido linkage, which are ascribed to the $\mathrm{N}-\mathrm{H}$ and $\mathrm{C}=\mathrm{O}$ stretching vibration of the acylamino group, respectively [10,11]. The absorption at about $1742 \mathrm{~cm}^{-1}$ is ascribed to the $\mathrm{C}=\mathrm{O}$ stretching vibration of the ester linkage, While at about $1698 \mathrm{~cm}^{-1}$ is ascribed to the $\mathrm{C}=\mathrm{O}$ stretching vibration of the carboxyl group.

Since coconut oil is a mixture of various triglycerides, the fatty acids of which consist of octanoic acid, decanoic acid, lauric acid, myristic acid, palmitic acid, stearic acid and a few unsaturated fatty acids $[15,16]$. Consequently, the target product cocoyl glycine is also a mixture including a series of compounds with different acyl chain length.

Full-scan mass spectrum $\left(\mathrm{ESI}^{-}\right)$of cocoyl glycine is shown in Figure 4. $\mathrm{m} / \mathrm{z}=200.1,228.1,256.1,284.1$, $312.2,336.2,338.2$ and 340.3 are ascribed to octanoylglycine, decanoyl glycine, lauryl glycine, myristyl glycine, palmityl glycine, linoleoyl glycine, oleoyl glycine

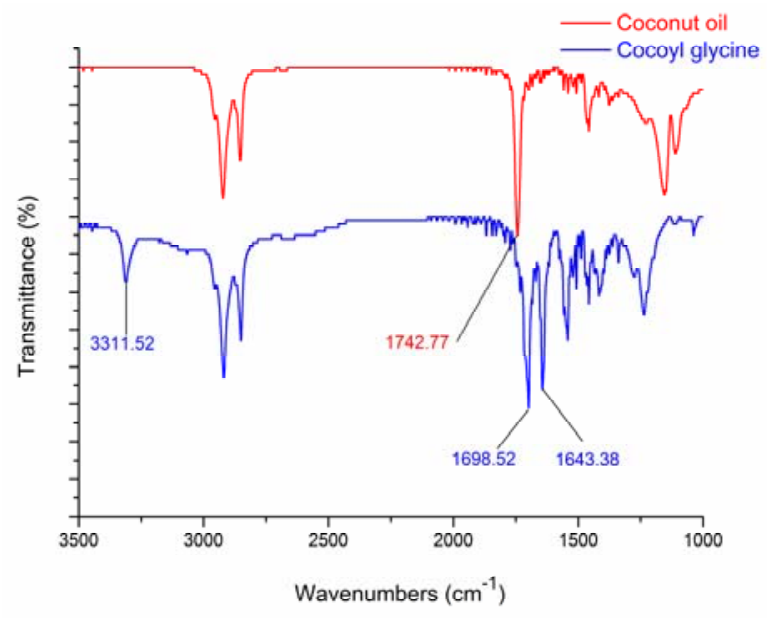

Figure 3. IR spectra of coconut oil and cocoyl glycine. 


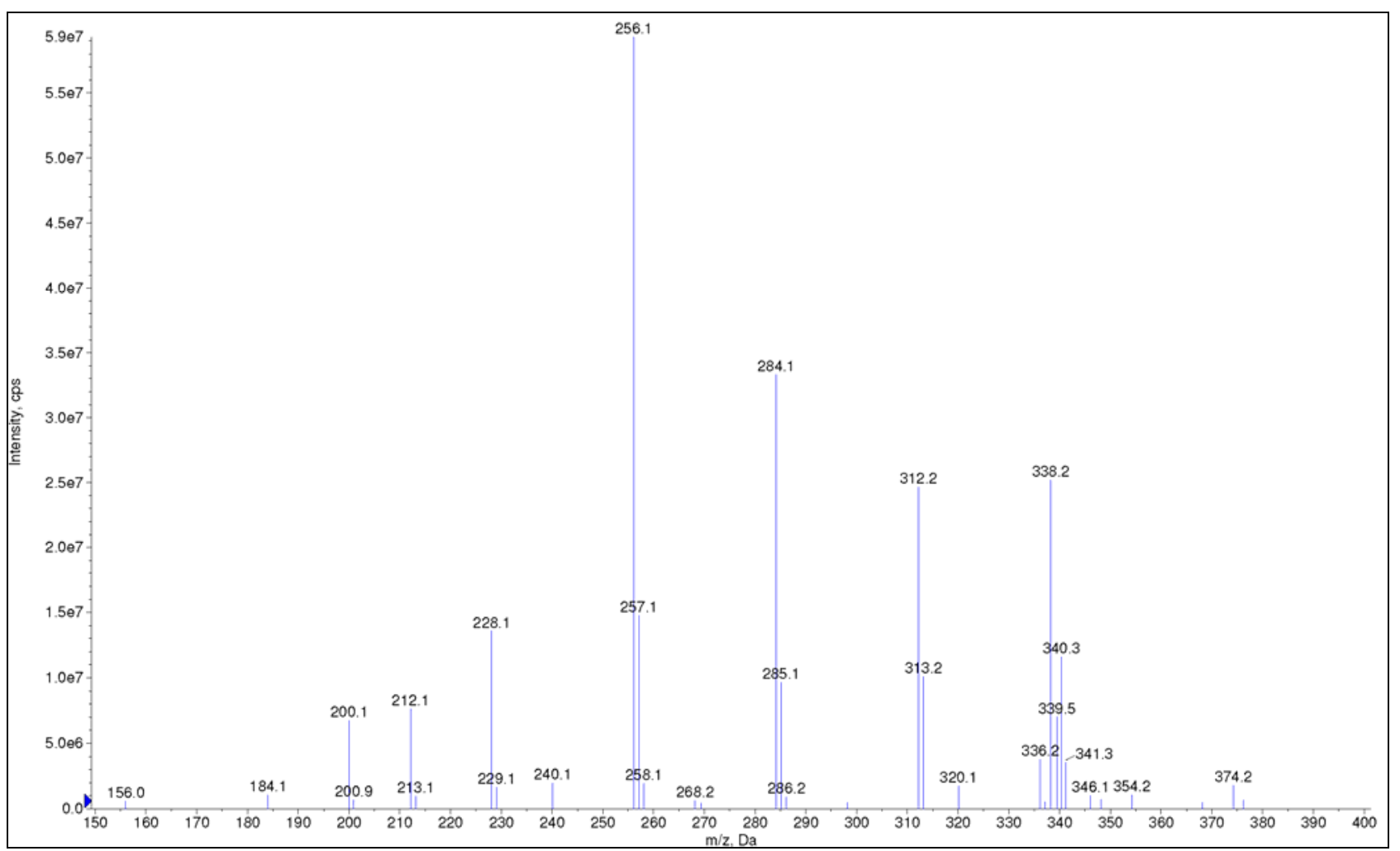

Figure 4. Full-scan mass spectrum of cocoyl glycine.

and stearyl glycine, respectively. These results are consistent with aforesaid expectation.

\subsection{LC/MS Analysis}

The surface properties of acyl amino acid surfactants are closely related to their structures, such as their acyl chain length [4]. It is essential to explore the composition of cocoyl glycine by LC/MS analysis.

The total ion chromatorgraphy of cocoyl glycine is shown in Figure 5. Ascription of each single peak is according to mass spectra at corresponding retention time, shown in Figure 6. While the mass spectrum at $17.39 \mathrm{~min}$ (C18:2) is not listed due to weak singals.

It is also shown that cocoyl glycine consists of a series of acyl glycines with different acyl chain length according to LC/MS results. A summary of the data is complied in Table 1.

The most prominent component in cocoyl glycine is lauryl glycine (C12:0) (43\%), and myristyl glycine (C14:0) (21\%) takes the second place. Besides a series of saturated homologous compounds, there are also a few unsaturated acyl glycines $(\mathrm{C} 18: 1, \mathrm{C} 18: 2)(7 \%, 1 \%)$ in the mixture.

This outcome is approximately in line with the reported results about fatty acid composition of coconut oil $[15,16]$, which indicates that acylation of glycine has no selectivity for fatty acids with different chain length.

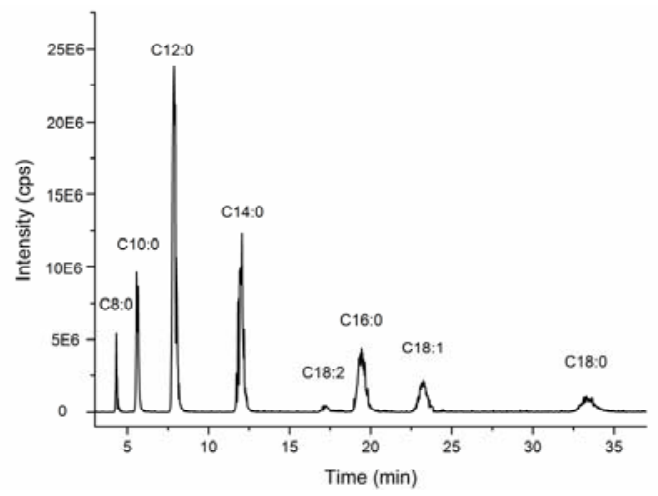

Figure 5. Total ion chromatorgraphy of cocoyl glycine.

Table 1. The composition of cocoyl glycine.

\begin{tabular}{cccc}
\hline $\begin{array}{c}\text { Acyl chain } \\
\text { length }\end{array}$ & $\begin{array}{c}\text { Retention Time } \\
(\mathrm{min})\end{array}$ & $m / z(\mathrm{Da})$ & $\begin{array}{c}\text { Peak area } \\
(\%)\end{array}$ \\
\hline C8:0 & 4.32 & 200.1 & 5 \\
C10:0 & 5.65 & 228.2 & 9 \\
C12:0 & 7.88 & 256.1 & 43 \\
C14:0 & 11.97 & 284.1 & 21 \\
C16:0 & 19.39 & 312.1 & 10 \\
C18:2 & 17.39 & 336.2 & 1 \\
C18:1 & 23.33 & 338.2 & 7 \\
C18:0 & 33.52 & 340.3 & 4 \\
\hline
\end{tabular}




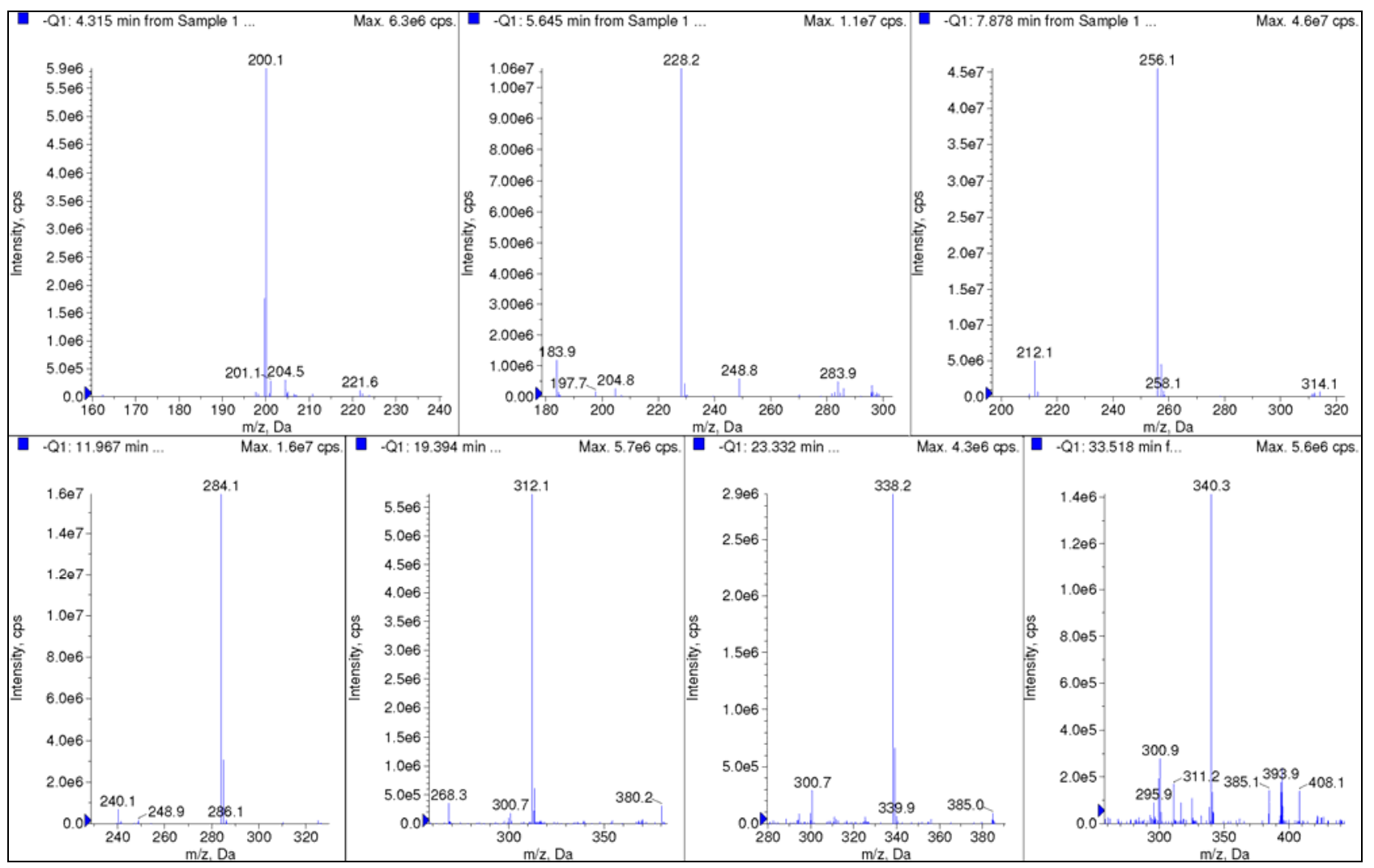

Figure 6. Mass spectra at $4.32 \mathrm{~min}, 5.65 \mathrm{~min}, 7.88 \mathrm{~min}, 11.97 \mathrm{~min}, 19.39 \mathrm{~min}, 23.33 \mathrm{~min}$ and $33.52 \mathrm{~min}$, respectively.

\subsection{Equilibrium Surface Tension Measurements}

The synthesized cocoyl glycine is in its acidic form, having free carboxylic group. Since the surface activity of surfactants is ensured by the presence of both hydrophilic and hydrophobic parts, the cocoyl glycine was neutralized with a $\mathrm{NaOH}$ solution in order to provide the affinity for water.

The equilibrium surface tensions of dilute aqueous solutions of sodium cocoyl glycinate were measured and shown in Figure 7.

The minimum surface tension $\left(\gamma_{\mathrm{CMC}}\right)$ values were acquired by analyzing the plateau region of the plots. The critical micelle concentrations (CMC) of sodium cocoyl glycinate were acquired by analyzing the intersection point of the plateau region and the steeply downward sloping portion of the plots.

The surface excess of sodium cocoyl glycinate at the CMC $\left(\Gamma_{\max }\right)$ was obtained from the Gibbs absorption equation:

$$
\Gamma_{\max }=-\frac{1}{2.303 n R T}\left(\frac{\partial \gamma}{\partial \log C}\right)_{T}
$$

where $\gamma$ represents the surface tension in $\mathrm{mN} \cdot \mathrm{m}^{-1}, R$ is the gas constant $\left(8.3144 \mathrm{~J} \cdot \mathrm{mol}^{-1} \cdot \mathrm{K}^{-1}\right)$, $\mathrm{T}$ is absolute temperature, $C$ is surfactant concentration, $\partial \gamma / \partial \log C$ was obtained from the slope of the linear surface tension $(\gamma)$

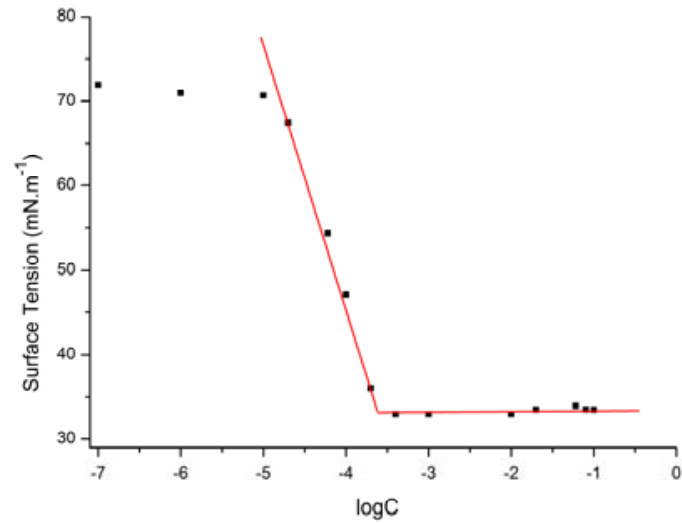

Figure 7. Plot of equilibrium surface tensions of aqueous solution of sodium cocoyl glycinate versus log mole concentration.

versus $\log C$ plot. In our solution, we can set $n=1$ [17].

The minimum area of the amphiphile head group at the surfactant saturated monolayer at the air/solution interface $\left(A_{\min }\right)$ was obtained from the relation:

$$
A_{\min }=\frac{10^{18}}{N_{A} \Gamma_{\max }}
$$

where $N_{A}$ is Avogadro's number.

The free energy of micellization $(\Delta \mathrm{G})$ of sodium cocoyl glycinate was obtained from the $\mathrm{CMC}$ value. 


$$
\Delta G=R T \ln \left(\frac{C M C}{55.5}\right)
$$

The interfacial parameters are presented in Table 2.

Sodium cocoyl glycinate reduced the surface tension of water to a minimum value of approximately 33 $\mathrm{mN} \cdot \mathrm{m}^{-1}$ at the $\mathrm{CMC}$ of $0.21 \mathrm{mmol} \cdot \mathrm{L}^{-1}$. While the CMC of sodium lauroyl glycinate was $12 \mathrm{mmol} \cdot \mathrm{L}^{-1}$ [18], which is higher than that of sodium cocoyl glycinate by two orders of magnitude [18]. Similarly, the CMC of sodium lauroyl sarcosinate produced was $14.3 \mathrm{mmol} \cdot \mathrm{L}^{-1}$ at $298 \mathrm{~K}$ [19], which is also much higher than that of sodium cocoyl glycinate [19]. For sodium salts of stearoyl amino acids, the $\mathrm{CMC}$ was about $10^{-3}$ magnitude [20], which is higher than that of sodium cocoyl glycinate by one order of magnitude as well.

The $\Gamma_{\max }$ value of sodium cocoyl glycinate is larger than that of sodium lauroyl sarcosinate, while the $A_{\min }$ is less than the latter [19]. This results from smaller hydrophilic head group of glycinate. The $\Delta \mathrm{G}$ value reveals that the process of micellization in solution is thermodynamically favored.

\section{Conclusions}

Cocoyl glycine was synthesized using coconut oil and sodium glycinate as raw materials. To the best of our knowledge, this is the first time to employ oil (fatty acid glyceride) as acylation regent rather than fatty acyl chloride to prepare acyl amino acid surfactants.

The structure and composition of cocoyl glycine have been identified by IR, ESI-MS and LC/MS analysis. The results showed that cocoyl glycine consists of a series of acyl glycines with different acyl chain lengths, and the proportion of each component is consistent with the composition of fatty acids derived from coconut oil.

The equilibrium surface tension results showed that sodium cocoyl glycinate possesses considerably lower $\mathrm{CMC}$ than that of sodium lauroyl glycinate, sodium lauroyl sarcosinate, and sodium salts of stearoyl amino acids as well, which may be related to its multi-constituents. It is very attractive to investigate the composition-property relationship of sodium cocoyl glycinate

Table 2. Interfacial parameters of sodium cocoyl glycinate.

\begin{tabular}{cc}
\hline Parameters & Values \\
\hline $\mathrm{CMC}\left(\mathrm{mmol} \cdot \mathrm{L}^{-1}\right)$ & 0.21 \\
$\gamma_{\mathrm{cmc}}\left(\mathrm{mN} \cdot \mathrm{m}^{-1}\right)$ & 33.1 \\
$\Gamma_{\max }\left(\mu \mathrm{mol} \cdot \mathrm{m}^{-2}\right)$ & 5.4 \\
$A_{\min }\left(\mathrm{nm}^{2} \cdot \mathrm{mol}^{-1}\right)$ & 0.31 \\
$\Delta \mathrm{G}\left(\mathrm{KJ} \cdot \mathrm{mol}^{-1}\right)$ & -30.9 \\
\hline
\end{tabular}

and other oleo-based amino acid surfactants thoroughly.

\section{Acknowledgements}

This work was supported by a grant from the National Natural Science Foundation of China (No. 21176004, 21203005), the National High Technology Research and Development Program of China (863 Program, No. 2012AA021502), the National Key Technologies Research and Development Program of China during the 12th Five-Year Plan Period (No. 2013BAC01B04), Funding Project for Training excellent talents of Beijing (No. 2011D005003000013).

\section{REFERENCES}

[1] R. S. Lanigan, "Final Report on the Safety Assessment of Cocoyl Sarcosine, Lauroyl Sarcosine, Myristoyl Sarcosine, Oleoyl Sarcosine, Stearoyl Sarcosine, Sodium Cocoyl Sarcosinate, Sodium Lauroyl Sarcosinate, Sodium Myristoyl Sarcosinate, Ammonium Cocoyl Sarcosinate, and Ammonium Lauroyl Sarcosinate," International Journal of Toxicology, Vol. 20, No. 1, 2001, pp.1-14. doi:10.1080/10915810152902547X

[2] G. O. Reznik, P. Vishwanath, M. A. Pynn, J. M. Sitnik, J. J. Todd, J. Wu, et al., "Use of Sustainable Chemistry to Produce an Acyl Amino Acid Surfactant," Applied Microbiology and Biotechnology, Vol. 86, No. 5, 2010, pp. 1387-1397. doi:10.1007/s00253-009-2431-8

[3] A. Hartmann and G. Speit, "The Contribution of Cytotoxicity to DNA Effects in the Single Cell Gel Test (comet assay)," Toxicology Letters, Vol. 90, No. 2-3, 1997, pp. 183-188. doi:10.1016/S0378-4274(96)03847-7

[4] J. D. Xia, Y. M. Xia and I. A. Nnanna, "Structure-Function Relationship of Acyl Amino Acid Surfactants: Surface Active and Antimicrobial Properties," Journal of Agricultural and Food Chemistry, Vol. 43, No. 4, 1995, pp. 867-871. doi:10.1021/jf00052a004

[5] P. Mary and D. D. Bendejacq, "Interactions between Sulfobetaine-Based Polyzwitterions and Polyelectrolytes," Journal of Physical Chemistry B, Vol. 112, No. 8, 2008, pp. 2299-2310. doi:10.1021/jp0769274

[6] E. Jungermann, J. F. Gerecht and I. J. Krems, "The Preparation of Long Chain N-Acylamino Acids," Journal of the American Chemical Society, Vol. 78, No. 1, 1956, pp. 172-174. doi:10.1021/ja01582a049

[7] R. Bordes and K. Holmberg, "Physical Chemical Characteristics of Dicarboxylic Amino Acid-based Surfactants," Colloids and Surfaces A: Physicochemical and Engineering Aspects, Vol. 391, No. 1-3, 2011, pp. 32-41. doi:10.1016/j.colsurfa.2011.03.023

[8] M. Gerova, F. Rodrigues, J.-F. Lamère, A. Dobrev and S. Fery-Forgues, "Self-assembly Properties of Some Chiral N-Palmitoyl Amino Acid Surfactants in Aqueous Solution," Journal of Colloid and Interface Science, Vol. 319, No. 2, 2008, pp. 526-533. doi:10.1016/j.jcis.2007.12.004

[9] M. Hassanzadeh, M. Kambarani, L. Tayebi, F. Yazdian, "Kinetic Study of Sodium Cocoyl Sarcosinate Synthesis 
and Factors Affecting the Reaction on Bench and Pilot Scales," Journal of Surfactants and Detergents, Vol. 15, No. 5, 2012, pp. 551-556. doi:10.1007/s11743-012-1333-4

[10] S.-F. Wang, T. Furuno and Z. Cheng, "Synthesis of New Amino Acid-type Amphoteric Surfactants from Tall Oil Fatty Acid," Journal of Wood Science, Vol. 47, No. 6, 2001, pp. 470-475. doi:10.1007/BF00767900

[11] T. Izumi, Y. Yagimuma and M. Haga, "Enzymatic Syntheses of N-Lauroyl- $\beta$-Alanine Homologs in Organic Media," Journal of the American Oil Chemists' Society, Vol. 74, No. 7, 1997, pp. 875-878. doi:10.1007/s11746-997-0231-9

[12] R. Valivety, P. Jauregi, I. Gill and E. Vulfson, "ChemoEnzymatic Synthesis of Amino Acid-Based Surfactants," Journal of the American Oil Chemists' Society, Vol. 74, No. 7, 1997, pp. 879-886. doi:10.1007/s11746-997-0232-8

[13] L. Goujard, M.C. Figueroa and P. Villeneuve, "ChemoEnzymatic Synthesis of N-Arachidonoyl Glycine," Biotechnology Letters, Vol. 26, No. 15, 2004, pp. 1211-1216. doi:10.1023/B:BILE.0000036597.25673.33

[14] H. Bidin, M. Basri, S. M. Radzi, A. Ariff, R. N. Z. R. A. Rahman and A. B. Salleh, "Optimization of LipaseCatalyzed Synthesis of Palm Amino Acid Surfactant Using Response Surface Methodology (RSM)," Industrial Crops and Products, Vol. 30, No. 2, 2009, pp. 206-211. doi:10.1016/j.indcrop.2009.03.006

[15] K. A. G. Gopala, R. Gaurav, S. B. Ajit, K. P. K. Prasanth and C. Preeti, "Coconut Oil: Chemistry, Production and Its Applications-A Review," Indian Coconut Journal,
Vol. 73, No. 3, 2010, pp.15-27.

[16] E. M. A. Dauqan, H. A. Sani, A. Abdullah and Z. M. Kasim. "Fatty Acids Composition of Four Different Vegetable Oils (Red Palm Olein, Palm Olein, Corn Oil and Coconut Oil) by Gas Chromatography," 2011 2nd International Conference on Chemistry and Chemical Engineering, Chengdu, China, 29-31 July 2011, pp. 31-34. http://www.ipcbee.com/vol14/6-C016.pdf

[17] T. Yoshimura, A. Sakato, K. Tsuchiya, T. Ohkubo, H. Sakai, M. Abe, et al., "Adsorption and Aggregation Properties of Amino Acid-based N-alkyl Cysteine Monomeric and N,N'-Dialkyl Cystine Gemini Surfactants," Journal of Colloid and Interface Science, Vol. 308, No. 2, 2007, pp. 466-473. doi:10.1016/j.jcis.2006.11.038

[18] V. Dana, P. Aurelia, E. C. Irina and C. C. Mihai, "Aspects Regarding the Synthesis and Surface Properties of Some Glycine Based Surfactants," Scientific BulletinUniversitatea Politehnica din Bucuresti, Series B, Vol. 73, No. 3, 2011, pp. 147-154.

[19] G. B. Ray, S. Ghosh and S. P. Moulik, "Physicochemical Studies on the Interfacial and Bulk Behaviors of Sodium N-Dodecanoyl Sarcosinate (SDDS)," Journal of Surfactants and Detergents, Vol. 12, No. 2, 2009, pp. 131-143. doi:10.1007/s11743-008-1105-3

[20] A. Sivasamy, M. Krishnaveni and P.G. Rao, "Preparation, Characterization, and Surface and Biological Properties of N-Stearoyl Amino Acids," Journal of the American Oil Chemists' Society, Vol. 78, No. 9, 2001, pp. 897-902. doi:10.1007/s11746-001-0361-5 